\title{
PERAN BADAN PEMBINAAN KEAGAMAAN DALAM PEMBINAAN KEAGAMAAN MAHASISWA DI FAKULTAS EKONOMI DAN ILMU SOSIAL UIN SULTAN SYARIF KASIM RIAU
}

\author{
Muslim Junhadi \\ Dosen Fakultas Ekonomi dan Ilmu Sosial \\ Universitas Islam Negeri Sultan Syarif Kasim Riau \\ email : $\underline{\text { muslim@uin-suska.ac.id }}$ \\ Junhadi \\ Dosen Fakultas Ekonomi dan Ilmu Sosial \\ Universitas Islam Negeri Sultan Syarif Kasim Riau \\ email : junhadi@uin-suska.ac.id
}

\begin{abstract}
Abstrak
Pengembangan status dari Institut Agama Islam Negeri Sultan Syarif Qasim Pekanbaru (IAIN Susqa Pekanbaru) menjadi Universitas Islam Negeri Sultan Syarif Kasim (UIN Suska) Riau, memberikan perubahan bagi lambaga ini. Hasil dari pengembangan dari institut menjadi universitas berdirinya fakultas-fakultas baru yang sifat pengembangan ilmunya dikenal sebagai "ilmu umum". Salah satu fakultas tersebut ialah Fakultas Ekonomi dan Ilmu Sosial (Fekonsos), dimana mayoritas mahasiswanya berlatar belakang pendidikan non-madrasah. Kondisi ini menuntut Fekonsos lebih fokus melakukan pembinaan di bidang keagamaan, agar tercipta integrasi keilmuan seperti apa yang dicita-citakan oleh UIN Suska Riau. Berdirinya Badan Pembinaan Keagamaan (BPK) Fekonsos sebagai jawaban atas persoalan yang dihadapi, BPK berperan dalam melakukan pembinaan yang meliputi pembinaan tauhid, ibadah, akhlak, muamalah dan menjalankan sunnah. Pembinaan terus dilakukan secara konsisten dan berkelanjutan baik berupa pembinaan yang teritegritas dalam keseharian maupun kegiatan temporer yang dilakukan oleh Fakultas Ekonomi dan Ilmu Sosial UIN Suska Riau.
\end{abstract}

Kata Kunci : keagamaan, tauhid, ibadah, akhlak, muamalah, sunnah

\section{PENDAHULUAN}

Pergerakan dan pertumbuhan manusia serta peningkatan kebutuhan hidup, mendorong seorang atau sekolompok orang untuk melakukan perubahan. Begitu juga terjadi pada organisasi dimana subyek dan obyeknya ialah manusia yang merupakan makhluk dinamis. Perubahan organisasi sudah dikaji secara ilmiah dalam teori-teori organisasi, organisasi yang mampu untuk berubah akan menjadi organisasi yang eksis, sedangkan yang tidak mengalami perubahan baik bentuk maupun sifatnya akan terjadi "gempa" di dalam organisasi tersebut yang berujung pada kematian (bubar).

Universitas Islam Negeri Sultan Syarif Kasim (UIN Suska) Riau merupakan pengembangan dari Institut Agama Islam Negeri Sultan Syarif Qasim Pekanbaru (IAIN Susqa Pekanbaru). Pengembangan ini dengan cara merubah status dari institut menjadi universitas dengan ditetapkannya Surat Keputusan Presiden Nomor 2 tahun 2005 tanggal 2 Februari 2005 tentang Perubahan Status Institut Agama Islam Negeri Sultan Syarif Qasim Pekanbaru menjadi Universitas Islam Negeri Sultan Syarif Kasim Riau. 
Hasil dari pengembangan dari institut menjadi universitas berdirinya fakultasfakultas baru yang sifat pengembangan ilmunya dikenal sebagai "ilmu umum". Salah satu fakultas tersebut ialah Fakultas Ekonomi dan Ilmu Sosial (Fekonsos). Selain disiplin Ilmu Ekonomi dan Ilmu Sosial yang diajarkan pada Fakultas Ekonomi dan Ilmu Sosial, untuk membekali dan menciptakan sumber daya yang luas ilmu dan wawasannya, tinggi etos kerjanya, mulia akhlaknya dan mantap ibadahnya, dibutuhkan ilmu agama sehingga terintegrasi dan inheren dalam setiap diri lulusan yang dihasilkan. Adapun mata kuliah keagamaan yang terdiri dari Studi Al-Qur'an, Studi Hadist, Aqidah Akhlak, Fiqih, Sejarah Peradaban Islam dan Pengantar Studi Islam, dan ditambah Bahasa Arab.

Fakultas Ekonomi dan Ilmu Sosial dalam mempersipkan lulusan seperti di atas, dibentuklah suatu lembaga yang disebut dengan Badan Pembinaan Keagamaan (BPK) untuk menjamin integrasi ilmu terlaksana dengan baik dan sebagai wadah pembinaan mahasiswa. Hal ini sangat dibutuhkan, disebabkan mahasiswa pada fakultas tersebut mayoritas berlatar belakang pendidikan nonmadrasah. Dekan sebagai pimpinan di fakultas menetapkan keputusan yang berisikan :

1. Kegiatan peningkatan pengetahuan dan penanaman nilai-nilai keislaman wajib diikuti oleh seluruh mahasiswa Fakultas Ekonomi dan Ilmu Sosial UIN Sultan Syarif Kasim Riau.

2. Kegiatan peningkatan pengetahuan dan penanaman nilai-nilai keislaman dilaksanakan oleh Badan Pembinaan Keagamaan Fakultas Ekonomi dan Ilmu Sosial (BPK-FEIS) UIN Suska Riau.

3. Sertifikat kelulusan mengikuti kegiatan peningkatan pengetahuan dan penanaman nilai-nilai keislaman menjadi syarat bagi mahasiswa untuk mengikuti Ujian Oral Komprehensip (ujian sarjana)
4. Mekanisme pelaksanaan peningkatan pengetahuan dan penanaman nilai-nilai keislaman secara teknis akan diatur oleh Badan Pembinaan Keagamaan Fakultas Ekonomi dan Ilmu Sosial (BPK-FEIS) UIN SUSKA RIAU.

\section{TINJAUAN PUSTAKA \\ 2.1. Dasar Dan Tujuan Pembinaan Keagamaan}

Dasar dari pembinaan keagamaan ini adalah Al-Qur'an dan Hadist. Di dalam AlQur'an surat Ali Imran ayat 104 disebutkan yang artinya :

"Dan hendaklah di antara kamu ada segolongan orang yang menyeru kepada kebajikan, menyuruh (berbuat) yang ma'ruf, dan mencegah dari yang mungkar. Dan mereka itulah orang-orang yang beruntung."'(QS. Ali Imran : 104).

Hadist Nabi Muhammad SAW mengatakan yang artinya :

"Barang siapa diantara kalian melihat kemunkaran, hendaknya ia mengubahnya dengan tangannya, apabila tidak mampu, hendaknya ia mengubahnya dengan lisannya, apabila tidak mampu, hendaknya ia mengubahnya dengan hatinya, dan itu adalah selemah-lemahnya iman." (H.R. Muslim).

Memperhatikan ayat dan hadist di atas, maka menganjurkan kepada manusia untuk menyeruh kepada yang ma'ruf dan mencegah dari kemungkaran, sehingga manusia itu akan tahu tujuan dari hidupnya. Selaras dengan itu, tujuan dari pembinaan keagamaan adalah agar manusia dalam hal ini mahasiswa memahami dan memiliki pengetahuan tentang agama Islam serta dapat menerapkannya dalam bentuk ibadah yang berlandaskan kepada Al-Qur'an dan Hadist. Intinya adalah meningkatkan keimanan dan ketaqwaan kepada Allah SWT dan bertingkah laku yang baik dalam kehidupan keseharian. 


\section{Metode Penelitian}

\subsection{Jenis Penelitian}

Penelitian yang dilakukan mengunakan pendekatan survey dengan tingkat ekplanasi analisis deskriptif kualitatif, yaitu suatu metode yang memberikan gambaran dan pemaparan fenomena ataupun gambaran situasi berdasarkan data-data yang ada. Kemudian diteruskan dengan melakukan interpretasi dan menganalisis hingga dapat ditarik kesimpulan.

\subsection{Tempat dan Waktu Penelitian}

Penelitian ini dilakukan di Fakultas Ekonomi dan Ilmu Sosial Universitas Islam Negeri Sultan Syarif Kasim Riau Jl. H.R. Soebrantas KM. 18 Simpang Baru Panam, dan dilaksanakan selama 5 bulan dari Bulan Maret 2017 sampai dengan Bulan Juli 2017.

\subsection{Informan Penelitian}

Informan dalam penelitian ini, penulis klasifikasikan menjadi tiga komponen, yaitu sebagai berikut :

1. Dekan Fakultas Ekonomi dan Ilmu Sosial, selaku pimpinan fakultas dan Pembina serta Penanggung jawab Badan Pembinaan Keagamaan (BPK). Dekan dijadikan sebagai key informant dalam penelitian ini.

2. Pengelola Badan Pembinaan Keagamaan (BPK), terdiri dari :

\begin{tabular}{|c|l|c|}
\hline No & Jabatan & Jumlah \\
\hline 1 & Ketua & 1 \\
\hline 2 & Sekretaris & 1 \\
\hline 3 & Pembina & 3 \\
\hline \multicolumn{2}{|c|}{ Total } & 5 \\
\hline
\end{tabular}

\subsection{Jenis Dan Sumber Data}

\subsubsection{Data Primer}

Data ini diperoleh langsung dari pihak-pihak terkait dengan penelitian ini, berupa informasi tentang pelaksanaan pembinaan keagamaan terhadap mahasiswa oleh Badan Pembinaan Keagamaan (BPK) Fakultas Ekonomi dan Ilmu Sosial Universitas Islam Negeri Sultan Syarif Kasim Riau.

\subsubsection{Data Sekunder}

Data ini diperoleh dari dokumen, laporan dan arsip pihak terkait yang berkenaan dengan penelitian ini, seperti antara lain:

1. Data jumlah mahasiswa Fakultas Ekonomi dan Ilmu Sosial Universitas Islam Negeri Sultan Syarif Kasim Riau.

2. Data yang berkaitan dengan Badan Pembinaan Keagamaan (BPK) Fakultas Ekonomi dan Ilmu Sosial Universitas Islam Negeri Sultan Syarif Kasim Riau.

3. Ruang lingkup program pembinaan oleh Badan Pembinaan Keagamaan (BPK) Fakultas Ekonomi dan Ilmu Sosial Universitas Islam Negeri Sultan Syarif Kasim Riau.

\subsection{Teknik Pengumpulan Data}

Untuk memperoleh data yang berhubungan dengan penelitian ini, penulis melakukan dengan cara:

1. Observasi, Yaitu pengamatan langsung di lapangan terhadap pembinaan keagamaan terhadap mahasiswa di Fakultas Ekonomi dan Ilmu Sosial Universitas Islam Negeri Sultan Syarif Kasim Riau.

2. Wawancara, Yaitu dengan melakukan wawancara langsung dengan informan penelitian, yaitu dengan pimpinan dan anggota Badan Pembinaan Keagamaan (BPK), Dekan Fakultas Ekonomi dan Ilmu Sosial, dan mahasiswa Fakultas Ekonomi dan Ilmu Sosial Universitas Islam Negeri Sultan Syarif Kasim Riau.

3. Dokumentasi, yaitu dengan memperoleh data-data dari dokumentasi, seperti data jumlah dosen, mahasiswa, program pembinaan Badan Pembinaan Keagamaan (BPK), struktur Fakultas, dan lain-lain yang berkaitan dengan penelitian.

\subsection{Teknik Analisis Data}

Mengingat penelitian ini berbentuk deskriptif, maka analisa data yang digunakan adalah analisa data deskriptif kualitatif, dengan cara apabila data telah terkumpul, lalu diinterpretasikan dengan pendekatan teori kemudian dipisahkan 
menurut kategori untuk memperoleh kesimpulan.

\section{PEMBAHASAN}

\subsection{Ruang Lingkup Pembinaan oleh Badan Pembina Keagamaan (BPK)}

Adapun yang menjadi ruang lingkup pembinaan oleh Badan Pembina Keagamaan (BPK) terdiri dari:

\subsubsection{Penanaman Tauhid}

Tauhid berasal dari bahasa arab yakni adalah mashdar (kata benda) yang berasal dari kata kerja yang artinya membuat sesuatu menjadi satu. Adapun secara istilah agama, tauhid artinya mengimani keberadaan Allâh, mengesakan Allâh Subhanahu wa Ta'ala.

Dari hasil pengkajian terhadap dalildalil tauhid yang dilakukan para ulama sejak dahulu hingga sekarang, mereka menyimpulkan bahwa ada tauhid terbagi menjadi tiga: Tauhid Rububiyah, Tauhid Uluhiyah dan Tauhid Al Asma Was Shifat.

\section{Tauhid Rububiyyah adalah} mentauhidkan Allah dalam kejadiankejadian yang hanya bisa dilakukan oleh Allah, serta menyatakan dengan tegas bahwa Allah Ta'ala adalah Rabb, Raja, dan Pencipta semua makhluk, dan Allahlah yang mengatur dan mengubah keadaan mereka. Meyakini rububiyah yaitu meyakini kekuasaan Allah dalam mencipta dan mengatur alam semesta, misalnya meyakini bumi dan langit serta isinya diciptakan oleh Allah, Allahlah yang memberikan rizqi, Allah yang mendatangkan badai dan hujan, Allah menggerakan bintang-bintang, dan lainlain. Di nyatakan dalam Al Qur'an:

Segala puji bagi Allah yang telah menciptakan langit dan bumi dan Mengadakan gelap dan terang" (QS. Al An'am: 1)

Dan perhatikanlah baik-baik, tauhid rububiyyah ini diyakini semua orang baik mukmin, maupun kafir, sejak dahulu hingga sekarang. Bahkan mereka menyembah dan beribadah kepada Allah. Hal ini dikhabarkan dalam Al Qur'an:
Sungguh jika kamu bertanya kepada mereka (orang-orang kafir jahiliyah), 'Siapa yang telah menciptakan mereka?', niscaya mereka akan menjawab 'Allah'. (QS. Az Zukhruf: 87)

Oleh karena itu, kita dapati ayahanda dari Rasulullah shallallahu'alaihi wasallam bernama Abdullah, yang artinya hamba Allah. Padahal ketika Abdullah diberi nama demikian, Rasulullah shallallahu'alaihi wasallam tentunya belum lahir.

2. Tauhid Uluhiyyah adalah mentauhidkan Allah dalam segala bentuk peribadahan baik yang zhahir maupun batin, Iman Syafi'i berpendapat Tauhid Uluhiyyah berarti mengesahkan Allah Ta'ala dalam beribadah, dan ini merupakan hakikat tauhid. Barang siapa yang mengamalkannya, berarti ia telah memenuhi hak Allah Ta'ala, karena tauhid ini mencakup ikrar (pengakuan) akan Rububiyah Allah dan beriman kepada asma dan sifat-sifatNya. hal ini berdasarkan kepada dalil:

Hanya Engkaulah yang Kami
sembah, dan hanya kepada
Engkaulah Kami meminta
pertolongan” (Al Fatihah: 5)

Sedangkan makna ibadah adalah semua hal yang dicintai oleh Allah baik berupa perkataan maupun perbuatan. Apa maksud yang dicintai Allah? Yaitu segala sesuatu yang telah diperintahkan oleh Allah dan Rasul-Nya, segala sesuatu yang dijanjikan balasan kebaikan bila melakukannya. Seperti shalat, puasa, bershodaqoh, menyembelih (berkurban).

Maka seorang yang bertauhid uluhiyah hanya meyerahkan semua ibadah ini kepada Allah semata, dan tidak kepada yang lain. Sedangkan orang kafir jahiliyyah selain beribadah kepada Allah mereka juga memohon, berdoa, beristighotsah kepada selain Allah. Dan inilah yang diperangi Rasulullah, ini juga inti dari ajaran para Nabi dan Rasul 
seluruhnya, mendakwahkan tauhid uluhiyyah. Allah Ta'ala berfirman:

Sungguh telah kami utus Rasul untuk setiap umat dengan tujuan untuk mengatakan: 'Sembahlah Allah saja dan jauhilah thagut", (QS. An Nahl: 36)

Syaikh DR. Shalih Al Fauzan berkata: "Dari tiga bagian tauhid ini yang paling ditekankan adalah tauhid uluhiyah. Karena ini adalah misi dakwah para rasul, dan alasan diturunkannya kitabkitab suci, dan alasan ditegakkannya jihad di jalan Allah. Semua itu adalah agar hanya Allah saja yang disembah, dan agar penghambaan kepada selainNya ditinggalkan" (Lihat Syarh Aqidah Ath Thahawiyah).

3. Sedangkan Tauhid Al Asma' was Sifat adalah mentauhidkan Allah Ta'ala dalam penetapan nama dan sifat Allah, yaitu sesuai dengan yang Ia tetapkan bagi diri-Nya dalam Al Qur'an dan Hadits Rasulullah shallallahu'alaihi wasallam. Cara bertauhid asma wa sifat Allah ialah dengan menetapkan nama dan sifat Allah sesuai yang Allah tetapkan bagi diriNya dan menafikan nama dan sifat yang Allah nafikan dari diriNya, dengan tanpa tahrif, tanpa ta'thil dan tanpa takyif. Allah Ta'ala berfirman :

Hanya milik Allah nama-nama yang husna, maka memohonlah kepada-Nya dengan menyebut nama-nama-Nya (QS. Al A'raf: 180)

Dalam membina mahasiswa tentang pendalaman nilai-nilai tauhid agar terhindar dari perbuatan syirik dan khurofat, salah satu yang dilakukan oleh Badan Pembina Keagamaan (BPK) Fakultas Ekonomi dan Ilmu Sosial menyelenggarakan ruqiyah massal bagi mahasiswa terkhusus mahasiswa baru, dengan tujuan menghapus kepercayaan kepada makhluk (benda) yang dapat memberikan manfaat dalam kehidupan. Hasil dari proses ruqiyah tersebut terkumpul benda-benda yang diyakini sebagai azzimat (jimat) yang selalu dibawa oleh mahasiswa untuk menjaga diri dari gangguan.

Keyakinan seperti ini tentu sangat berbahaya bagi ketauhidan seorang mukmin, sehingga dari proses ruqiyah ini dapat menyadarkan mahasiswa untuk tidak percaya kepada kekuatan-kekuatan lain selain dari kekuatan Allah. Hanya Allah lah yang dapat memberikan manfaat dan mudhorat dalam kehidupan ini.

Selanjutnya, mengenalkan Ruqyah Syirkiyah yakni ruqyah yang mengandung kesyirikan, yaitu menggunakan kata-kata atau kalimat atau huruf-huruf tidak jelas, atau mengandung kekufuran, bukan bahasa Arab, baik dibacakan atau dituliskan di kertas, wadah, dan lainnya, bahkan pembacanya sendiri belum tentu tahu maknanya. Ini termasuk haram menurut ijma ulama, pelakunya tercela dan penggunanya berdosa besar. Kemudian mengenalkan Ruqyah Syariyyah yaitu mantera/jampi yang menggunakan ayat Alquran, Asmaul Husna, dzikir yang matsur (berasal dari Rasulullah), dan doa-doa perlindungan, dan bebas dari muatan syirik. Sebagaimana yang Rasulullah SAW rekomendasikan kepada sahabatnya, Auf bin Malik Radhiallahu Anhu. Banyak sekali riwayat dalam Shahihain (Bukhari Muslim) yang menyebutkan ruqyah dengan al-Quran.

Kemudian, memantapkan keyakinan sebagaimana yang termaktub dalam rukun iman, yakni iman kepada Allah, iman kepada Malaikat, imam kepada kitab-kitab Allah, Iman kepada Rasul, Imam kepada Hari Kiamat, dan iman kepada Qodho dan Qadar.

\subsubsection{Pembinaan Ibadah}

Ibadah secara bahasa (etimologi) berarti merendahkan diri serta tunduk. Sedangkan menurut syara' (terminologi), ibadah mempunyai banyak definisi, tetapi makna dan maksudnya satu. Definisi itu antara lain adalah: 
1. Ibadah adalah taat kepada Allah dengan melaksanakan perintah-Nya melalui lisan para Rasul-Nya.

2. Ibadah adalah merendahkan diri kepada Allah Azza wa Jalla, yaitu tingkatan tunduk yang paling tinggi disertai dengan rasa mahabbah (kecintaan) yang paling tinggi.

3. Ibadah adalah sebutan yang mencakup seluruh apa yang dicintai dan diridhai Allah Azza wa Jalla, baik berupa ucapan atau perbuatan, yang zhahir maupun yang bathin. Yang ketiga ini adalah definisi yang paling lengkap.

Ibadah terbagi menjadi ibadah hati, lisan, dan anggota badan. Rasa khauf (takut), raja' (mengharap), mahabbah (cinta), tawakkal (ketergantungan), raghbah (senang), adalah ibadah qalbiyah (hati). Sedangkan tasbih, tahlil, takbir, tahmid dan syukur dengan lisan adalah ibadah lisaniyah qalbiyah (lisan dan hati). Sedangkan shalat, zakat, haji, dan jihad adalah ibadah badaniyah qalbiyah (fisik dan hati). Serta masih banyak lagi macammacam ibadah yang berkaitan dengan amalan hati, lisan dan badan.

Allah Azza wa Jalla memberitahukan bahwa hikmah penciptaan jin dan manusia adalah agar mereka melaksanakan ibadah hanya kepada Allah Azza wa Jalla. Dan Allah Mahakaya, tidak membutuhkan ibadah mereka, akan tetapi merekalah yang membutuhkan-Nya, karena ketergantungan mereka kepada Allah, maka barangsiapa yang menolak beribadah kepada Allah, ia adalah sombong. Siapa yang beribadah kepada-Nya tetapi dengan selain apa yang disyari'atkan-Nya, maka ia adalah mubtadi' (pelaku bid'ah). Dan barangsiapa yang beribadah kepada-Nya hanya dengan apa yang disyari'atkan-Nya, maka ia adalah mukmin muwahhid (yang mengesakan Allah).

\subsubsection{Pilar-Pilar Ubudiyyah Yang Benar}

Sesungguhnya ibadah itu berlandaskan pada tiga pilar pokok, yaitu: hubb (cinta), khauf (takut), raja' (harapan). Rasa cinta harus disertai dengan rasa rendah diri, sedangkan khauf harus dibarengi dengan raja'. Dalam setiap ibadah harus terkumpul unsur-unsur ini. Allah berfirman tentang sifat hambahamba-Nya yang mukmin:

Dia mencintai mereka dan merekapun mencintai-Nya. (AlMaidah: 54)

Adapun orang-orang yang beriman sangat besar cinta-nya kepada Allah. (Al-Baqarah: 165)

Sesungguhnya mereka adalah orangorang yang selalu bersegera dalam (mengerjakan) kebaikan dan mereka berdo'a kepada Kami dengan penuh harap dan cemas. Dan mereka adalah orang-orang yang khusyu' kepada Kami. (Al-Anbiya': 90)

\subsubsection{Syarat Diterimanya Ibadah}

Ibadah adalah perkara tauqifiyah yaitu tidak ada suatu bentuk ibadah yang disyari'atkan kecuali berdasarkan Al-Quran dan As-Sunnah. Apa yang tidak disyari'atkan berarti bid'ah sebagaimana sabda Nabi Shallallahu 'alaihi wa sallam :

Barangsiapa yang beramal tanpa adanya tuntunan dari kami, maka amalan tersebut tertolak. (HR. Muslim)

Syarat yang pertama ialah ikhlas yang merupakan konsekuensi dari syahadat laa ilaaha illallaah, karena ia mengharuskan ikhlas beribadah hanya kepada Allah dan jauh dari syirik kepada-Nya. Sedangkan syarat kedua ialah Ittiba' yang merupakan konsekuensi dari syahadat Muhammad Rasulullah, karena ia menuntut wajibnya taat kepada Rasul, mengikuti syari'atnya dan meninggalkan ibadah-ibadah yang diada-adakan. Syaikhul Islam mengatakan, Inti agama ada dua pilar yaitu kita tidak beribadah kecuali hanya kepada Allah, dan kita tidak beribadah kecuali dengan apa yang Dia syari'atkan.

Melakukan pembinaan ibadah bagi mahasiswa Fekonsos tentu dimulai dari tatacara melakukan ibadah tersebut sebagaimana yang telah diajarakan oleh 
Rasulullah SAW, selanjutnya menanamkan kesadaran pentingnya melakukan ibadah dan konsisten di dalam melakukannya. Pembinaan diantranya meliputi :

1. Bersuci atau berthoharoh

2. Tatacara Tayammum

3. Beberapa istilah dalam ilmu Fiqh

4. Sholat

5. Penyelenggaraan Jenazah

6. Tatacara Sholat Jenazah

7. Syarat Syah Sholat Juma'ah

8. Syarat dan Rukun Khutbah

9. Sholat Jama' dan Qosor

10. Ilmu Tajwid (mentoring qur'an/tahsin)

11. Berzikir

\subsubsection{Pembinaan Akhlak}

Rasulullah Shallallahu 'alaihi wa sallam diutus untuk mengajak manusia agar beribadah hanya kepada Allah Azza wa Jalla saja dan memperbaiki akhlak manusia. Nabi Shallallahu 'alaihi wa sallam bersabda:

Sesungguhnya aku diutus untuk menyempurnakan akhlak yang baik. (HR. Al-Bukhari)

Allah SWT memuji akhlak Rasulullah SAW, dalam Al-Qu'ran Allah berfirman :

Dan sesungguhnya kamu benarbenar mempunyai akhlak yang agung. (Al-Qalam: 4)

Hal ini sesuai dengan penuturan 'Aisyah Radhiyallahu anhuma:

Rasulullah Shallallahu 'alaihi wa sallam adalah orang yang paling baik akhlaknya. (HR.Al-Bukhari)

Sesungguhnya antara akhlak dengan 'aqidah terdapat hubungan yang sangat kuat sekali. Karena akhlak yang baik sebagai bukti dari keimanan dan akhlak yang buruk sebagai bukti atas lemahnya iman, semakin sempurna akhlak seorang Muslim berarti semakin kuat imannya.

Akhlak yang baik adalah bagian dari amal shalih yang dapat menambah keimanan dan memiliki bobot yang berat dalam timbangan. Pemiliknya sangat dicintai oleh Rasulullah Shallallahu 'alaihi wa sallam dan akhlak yang baik adalah salah satu penyebab seseorang untuk dapat masuk Surga. Rasulullah Shallallahu 'alaihi wa sallam bersabda:

Tidak ada sesuatu pun yang lebih berat dalam timbangan seorang mukmin di hari Kiamat melainkan akhlak yang baik, dan sesungguhnya Allah sangat membenci orang yang suka berbicara keji dan kotor.(HR. At-Tirmidzi)

Beliau Shallallahu 'alaihi wa sallam bersabda pula:

Sesungguhnya yang paling aku cintai di antara kalian dan yang paling dekat majelisnya denganku pada hari Kiamat adalah yang paling baik akhlaknya...(HR. At-Tirmidzi)

Pembinaan yang sangat sulit ialah bagaimana membina akhlak manusia, karena sering sekali berbenturan dengan adat dan kebiasaan yang menjadi karakter seseorang atau sekelompok orang. Pembinaan akhlak ini sangat dibutuhkan, disebabkan mahasiswa pada Fakultas Ekonomi dan Ilmu Sosial mayoritas berlatar belakang pendidikan nonmadrasah, sehingga pembinaan akhlak mahasiswa tentu perlu penanganan khusus, BPK bersama dengan fakultas selalu melakukan pembinaan akhlak mahaiswa dengan cara menertibkan cara berbusana, pergaulan mahasiswa, melakukan kegiatan yang dapat membentuk akhlak mahasiswa, diantaranya kegiatan ketauladanan akhlak Rasulullah. Pembinaan ini juga bekerjasama dengan BEM Fakultas dan UKMF ISC Al-Iqtishod.

\subsubsection{Muamalah}

Muamalah dalam arti luas yaitu aturan-aturan atau hukum Allah untuk mengatur manusia dalam kaitannya dengan urusan duniawi dalam pergaulan sosial. Muamalah dalam arti khusus yaitu aturanaturan Allah yang wajib ditaati yang mengatur hubungan manusia dengan manusia dalam kaitannya dengan cara memperoleh dan mengembangkan harta benda. Sedangkan hukum mu'amalah, baik 
jual beli, sewa menyewa, dan semisalnya hukum asalnya adalah halal dan diperbolehkan kecuali ada dalil yang melarangnya.

Muamalah harus didasarkan pada kejujuran sehingga terwujud jenis muamalah yang baik dan adil. Kita dituntut untuk memberikan hak-hak kepada sipemiliknya, dan menjauhi segala apa yang bisa mendatangkan kemudhoratan bagi mereka dalam upaya untuk memperoleh hak-haknya masing-masing. Pembinaan dibidang muamalah secara khusus mahasiswa diajarkan fiqih muamalah dan mengenalkan ayat-ayat AlQuran dan Hadist tentang ekonomi dan bermuamlah yang disyaratkan dalam islam, serta memberikan pemahaman tentang perbuatan riba karena rusaknya ekonomi disebabkan oleh perbutan riba.

\subsubsection{Sunnah Merupakan Kunci Sukses}

Nabi Muhammad SAW telah diutus Allah Ta'ala sebagai penyeru ke jalan yang lurus, dan petunjuk yang lurus. Siapa yang mengikutinya, maka ia mendapatkan petunjuk dan selamat. Siapa yang bertentangan dengan atau menyelisihi jalannya, maka ia akan sesat dan binasa.

Muhammad Rasulullah SAW adalah pelita yang menerangi, dan bukti yang pasti. Allah Ta'ala menjadikan ketaatan kepada-Nya disandingkan dengan ketaatan kepadanya, dan keridhaan-Nya disandingkan dengan membenarkan dan menolongnya. Siapa yang menelantarkannya, ia akan ditelantarkan.

Allah Ta'ala berfirman dalam surah An-Nisa' ayat 80 :

Barang siapa yang mentaati Rasul, sesungguhnya ia telah mentaati Allah Ta'ala, dan barang siapa yang berpaling dari peringatannya, maka kami tidak mengutusmu untuk menjadi memelihara bagi mereka

Allah Ta'ala berfirman dalam surah Ali Imron ayat 31 :

Jika kamu (benar-benar) mencintai Allah, ikutilah aku, niscaya Allah mengasihi dan mengampuni dosa- dosamu". Allah Maha Pengampun lagi Maha Penyayang

Allah Ta'ala berfirman dalam surah AlHasyr ayat 7:

Apa yang diberikan Rasul kepadamu, maka terimalah. Dan apa yang dilarangnya bagimu, maka tinggalkanlah. Dan bertakwalah kepada Allah. Sesungguhnya Allah amat keras hukumannya.

Pada zaman ini sunnah menjadi hal yang aneh dan terpinggirkan dalam keseharian ummat islam, pada hal ini merupakan kunci sukses para sahabat di masa Rasulullah SAW. Abu Ad-Darda' ra. berkata seandainya Rasulullah SAW keluar kepada mereka, niscaya beliau tidak mengenali sedikitpun dari apa yang telah beliau dan para sahabat lakukan kecuali sholat. Perkataan ini menjelaskan betapa jauhnya generasi kita dari sunnah Nabi SAW, apakah dari akhlak kita, adab keseharian kita dan begitu pula dengan amal ibadah yang kita lakukan.

Rasulullah bersabda :

Akan datang pada manusia suatu zaman yang ketika itu orang yang bersabar diantara mereka atas perkara agamanya seperti orang yang menggenggam bara api (HR. At-Tirmizi)

Dalam riwayat lain:

Akan datang pada manusia suatu zaman yang ketika orang yang berpegang teguh dengan sunnahku, ketika ummat $k u$ berselisih, seperti orang yang menggenggam bara api (As-Silsilah Ash-Shahihah 2/646)

Adapun syarat yang harus kita penuhi dalam mengikuti sunnah Nabi SAW adalah:

1. Sebabnya

Apabila seseorang beribadah kepada allah ta'ala disertai sebab yang bukan dari syariat, maka hal ini akan bertentangan dengan sunnah, walaupun 
ibadah yang dilakukan baik dan disunnahkan. Sebagai contoh menghidupkan malam dengan cara melakukan sholat tahajjud pada malam tanggal 27 rojab, dengan alasan bahwa malam itu isra' mikrajnya nabi muhammad saw.

Sholat tahajjud merupakan ibadah yang disyariatkan, namun apabila disertai sebab yang tidak disyariatkan, maka ibadah ini akan menyelisihi sunnah nabi saw. Jadi dalam beribadah kita harus mengetahui sebab kita melakukan ibadah tersebut karena ini merupakan perkara yang penting.

2. Jenisnya

Apabila seseorang beribadah kepada allah ta'ala harus sesuai dengan jenis yang telah allah dan rasulullah tentukan, apabila menyelisihi maka ibadah tersebut tidak akan mendapat keredhoan allah ta'ala. Sebagai contoh apabila seseorang melakukan ibadah kurban dengan menyembelih seekor kuda atau ratusan ekor ayam, maka kurbannya tidak sah, karena jenis hewan yang dikurbankan bertentangan dengan yang disyariatkan dalam berkurban, maka kurban hanya sah dengan jenis hewan ternak yang disebut dengan bahiimah, seperti: unta, sapi dan domba (kambing)

3. Kadarnya

Seandainya seseorang menambahkan rokaat sholat fardu yang oleh allah dan rasulullah telah tentukan, maka sholatnya tidak diterima dan ini menyelisihi sunnah, karena bertentangan dengan syariat khususnya berkaitan dengan kadarnya (ukurannya)

4. Tata caranya

Ibadah yang telah dicontohkan oleh nabi saw mengenai tata caranya, maka kita harus mengikuti apa yang telah nabi saw contohkan dan tidak dibenarkan kita untuk menyelisihinya. Sebagai contoh melakukan wudhu', harus sesuai dengan yang nabi saw contohkan. Tidak benar kalau kita mulai dengan mencuci kedua kaki lalu membasuh kepala, atau kita bolak-balikkan susunan yang telah nabi ajarkan atau contohkan.

5. Waktunya

Ada ibadah kepada allah ta'ala yang ditentukan waktunya, seperti penyembelihan ibadah kurban hanya boleh dilakukan pada tanggal 10,11,12 dan 13 zulhijjah pada setiap tahunnya. Apabila diluar tanggal tersebut tidaklah termasuk ibadah kurban.

6. Tempatnya

Ada juga ibadah kepada allah ta'ala yang telah allah dan rasulullah tentukan tempatnya, seperti tawaf hanya boleh dilakukan mengelilingi ka'bah di makkah, dan juga wakuf hanya boleh dilakukan di arafah. Apa bila dilakukan ditempat lain, maka ibadah tersebut bertentangan dengan sunnah nabi SAW dan pasti binasa.

Pembinaan mahasiswa agar selalu memegang sunnah sebagai kunci suskes, BPK Fakultas Ekonomi dan Ilmu Sosial, melakukan kegaiatan Religius Education Tranning Youth (RETRY). Kegiatan ini mengajak mahasiswa untuk mengamalkan sunnah selama 24 jam, pelaksanaan kegiatan ini selama tiga hari dengan cara melakukan mabit (bermalam) di masjid dan musholla. Selama kegiatan tersebut mahasiswa menjalankan atau mengerjakan nilai-nilai sunnah dalam kehidupan, mulai dari bagun tidur sampai tidur kembali.

\section{Penutup}

\subsection{Kesimpulan}

1. Pengembangan status dari Institut Agama Islam Negeri Sultan Syarif Qasim Pekanbaru (IAIN Susqa Pekanbaru) menjadi Universitas Islam Negeri Sultan Syarif Kasim (UIN Suska) Riau, memiliki dampak positif dilihat dari pembangunan dan jumlah mahasiswa. Namun untuk menciptakan integritas keilmuan perlu disiapkan kurikulum dan metode yang terintegrasi di dalam proses perkuliahan.

2. Fakultas Ekonomi dan Ilmu Sosial sebagai salah satu fakultas yang pengembangan ilmunya dikenal sebagai 
"ilmu umum" diman mayoritas mahasiswanya berlatar belakang pendidikan non-madrasah, perlu pembinaan keagamaan yang konsisten dan berkelanjutan, agar apa yang menjadi visi dan misi UIN Suska Riau dan Fakultas Ekonomi dan Ilmu Sosial tercapai.

3. Kehadiran Badan Pembinaan Keagamaan (BPK) di Fakultas Ekonomi dan Ilmu Sosial dapat berperan dalam pembinaan keagamaan yang konsisten dan berkelanjutan, meliputi pembinaan tauhid, ibadah, akhlak, muamalah dan menjalankan sunnah.

\subsection{Saran}

1. Pembinaan keagamaan oleh Badan Pembinaan Keagamaan (BPK) hendaknya selalu ditingkatkan, terutama yang menyangkut tentang pembinaan akhlak dan ibadah.

2. Pembinaan Akhlak mahasiswa harus ditingkatkan dan melibatkan seluruh civitas akademika yang ada di fakultas.

3. Badan Pembinaan Keagamaan (BPK) harus selalu menjalin kerjasama dengan para ulama terutama di lingkungan UIN Suska Riau, sehingga menjadi kerisauan bersama dalam membina agama mahasiswa di UIN Suska Riau.

4. Pimpinan Fakultas Ekonomi dan Ilmu Sosial agar tetap selalu komitmen memberikan dukungan terhadap program pembinaan keagamaan sebagaimana yang telah diberikan selama ini.

\section{DAFTAR PUSTAKA}

Afif Abdullah Fattah Thabbarah. 1986. Dosa Dalam Pandangan Islam: Risalah Bandung

Azhari Ahmad Mahmud. 2014. Jangan

Tinggalkan Sunnah!: Pustaka Ibnu Umar

Daradjat, Zakiah. 2006. Ilmu Pendidikan Islam, Jakarta: PT. Bumi Aksara.

\section{Metodik Khusus}

Pengajaran Agama Islam, Jakarta: PT.

Bumi Aksara, 1995.
Hafid Abdullah. Kunci Fiqh Syafi'i : AsySyifa Semarang

Henrizal Hadi Wahab. 2013. Buku Panduan Pembinaan Keagamaan Mahasiswa Fakultas Ekonomi dan Ilmu Sosial, Fekonsos UIN Suska Riau.

Muhammad bin A.W. Al-'Aqil. 2009. Manhaj Aqidah Imam Asy-Syafi' $i$ : Pustaka Imam Asy-Syafi'i

Muhammad Nashiruddin Al-Albani. 2005. Sifat Sholat Nabi SAW : Gema Risalah Press 